\title{
Recovery of naringin from kinnow (Citrus reticulata Blanco) peels by adsorption-desorption technique using an indigenous resin
}

\author{
M LAXMI DEEPAK BHATLU, SATYA VIR SINGH* and ASHOK KUMAR VERMA \\ Department of Chemical Engineering and Technology, Indian Institute of Technology (Banaras Hindu \\ University), Varanasi 221005, India \\ e-mail: laxmi818@gmail.com; satyavirsingh59@ rediffmail.com
}

MS received 7 July 2015; revised 29 June 2016; accepted 6 July 2016

\begin{abstract}
A process technology has been developed for recovery of naringin from kinnow (citrus) peels, which is a waste. The kinnow peels were boiled with water to extract naringin into water. It was adsorbed on an indigenous macroporous resin, Indion PA-500. Naringin was recovered from the saturated resin by desorption with ethanol as a solvent. The equilibrium and kinetic studies for both adsorption and desorption are presented. The Langmuir isotherm described the adsorption equilibrium data. However, desorption data were best described by the Toth isotherm. Adsorption and desorption kinetic data were found to follow a pseudo-secondorder rate equation and second-order rate equation, respectively. Recovery of naringin was about $49 \% \mathrm{w} / \mathrm{w}$ (based on naringin present in peel-boiled extract). The purity of final products was $91-94 \% \mathrm{w} / \mathrm{w}$.
\end{abstract}

Keywords. Naringin; process development; adsorption; process technology; waste management.

\section{Introduction}

Kinnow (Citrus reticulata Blanco), a hybrid of King and Willow leaf mandarins, belongs to the family of citrus fruits and is an important fruit of India. Mandarins are characterized by easily peeled rind and open core and deeper orange color than is found in most other types of citrus fruits [1].

Kinnow fruit is grown widely in Punjab, Haryana, Rajasthan and Himachal Pradesh in India with an annual production equal to about 0.5 million tonnes [1]. Only about $10 \%$ of it is processed for juice extraction. During processing and utilization of kinnow fruit into various products, peel, pulp and seeds are generated as waste, which is conventionally used as animal feed. During juice extraction $30-40 \mathrm{wt} \%$ of kinnow peel is obtained [2]. It contains a few economically valuable products such as naringin $(0.6-1.0 \mathrm{~g} / \mathrm{kg}$ wet peels) and pectin.

Naringin is a flavonoid found in citrus fruits, having a bitter flavour. Its structure is given in figure 1. Its molecular weight, boiling point, melting point and vapour pressure are $580.54,928.1,166^{\circ} \mathrm{C}$ and $0 \mathrm{mmHg}$ at $25^{\circ} \mathrm{C}$, respectively [3]. It is a valuable compound and finds application in pharmaceutics [4] and food industry. It is used in the manufacture of powder drinks (citrus soft drinks and tonic), confectionery (bitter chocolate, ice creams and ices), marmalade and jams and a preservative against bacteria, fungi and yeast. In pharmaceutics, naringin exhibits antioxidant

*For correspondence activity, blood lipid lowering and anticancer activity. It reduces total cholesterol levels, enhances lipid metabolism, protects from carcinogenic matter and against toxins in chemotherapy drugs and the environment $[4,5]$.

If a suitable technology is developed for extraction and recovery of naringin, it will not only add value to citrus processing but also result in the reduction of the waste. It will thus be benefitting to kinnow growers and the society. To the best of our knowledge, the present study is the first attempt for the recovery of naringin from kinnow peels using the adsorption-desorption technique.

In view of the above, a cost-effective method for recovery of naringin from kinnow peels is required. Several techniques for naringin recovery from various citrus fruit peels have been reported in the literature [5-13]. Naringin was extracted from grapefruit (Citrus paradisi Macf.) seeds [6], Citrus junos peels [7] and Citrus paradisi [8] by supercritical carbon dioxide $\left(\mathrm{SC}-\mathrm{CO}_{2}\right)$ extraction. Naringin was also extracted with water followed by crystallization from bergamot peel [9] and pomelo (Citrus grandis) peel [10], and with ultrasonic extraction from Citrus grandis Tomentosa [11] and pomelo peel [12]. Calvarano et al [13] obtained naringin from bergamot (Citrus bergamia) peels with XAD-16 resin by adsorption followed by desorption with ethanol. Jiang et al [5] selected X-5 resin from five kinds of macroporous resins for naringin recovery from Shaddock peels due to high adsorption and easy desorption of naringin with eluant acetone.

The nonionic polystyrene divinylbenzene cross-linked polymeric adsorbents are being commercially exploited for 


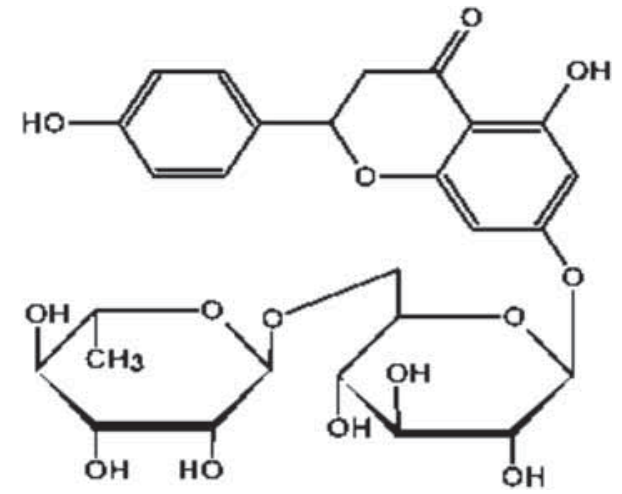

Figure 1. Structure of naringin.

debittering of citrus juices [14]. The macroporous adsorbents XAD-4, D380, ADS-17, ADS-21 and AB-8 [15], XAD-16 and SP825 [16], XAD-7 and XAD-4 [17], XAD-7 [18], p-phenylenediamine (PPDA), p-aminophenol and p-aminobenzoic acid (PANB) [19], XAD 16 [20], HPD100B, HPD300, AB-8 and HPD722 [21], XAD-7, XAD-4, AB-8 and ADS-17 [22], FPX-66, XAD-7HP, XAD-16 N, XAD-1180 and XAD-761 [23] are reported for the extraction of flavonoids.

In the present work, indigenous resin Indion PA-500 was used. It is a polystyrene-divinylbenzene-based adsorbent resin. The properties of polystyrene divinylbenzene polymeric resin suitable for naringin adsorption as mentioned by Manlan et al [24] are high cross-linking $>16 \%$, density about $1.2 \mathrm{~g} / \mathrm{ml}$ for proper submergence of resin beads, large specific surface area $>500 \mathrm{~m}^{2} / \mathrm{g}$ of dry adsorbent and low mean pore diameter of about $50-60{ }^{\circ} \mathrm{A}$. The adsorbent, Indion PA-500, is a macroporous, nonionic, hydrophobic and cross-linked polymer adsorbent resin. As mentioned by manufacturers, the pore size distribution in this adsorbent makes it an excellent choice for removal of large organic molecules from polar solvents. Naringin is a large molecule (MW 580) can be adsorbed from polar solvent water (kinnow-peel-boiled water-KPBW). The properties of the resin are suited for our purpose and therefore it is selected for studies after confirmation with preliminary experiments that the resin adsorbs naringin from KPBW, and naringin is desorbed from it with ethanol. The properties of the resin, as reported by the manufacturer, are presented in table 1 . The resin is very inexpensive in comparison with XAD-16 resin.

\section{Materials and methods}

Resin Indion PA-500, which is commercially available, was procured from Ion Exchange India Ltd. Naringin was purchased from Sigma Aldrich Chemicals. The chemicals hydrogen chloride, diethylene glycol, ethanol and citric acid were obtained from Merck Specialties Pvt. Limited.
Potassium metabisulphite and sodium hydroxide were purchased from Qlualigens Fine Chemicals Limited. The chemicals used were of analytical reagent grade. For the preparation of all solutions, distilled water was used. Kinnow peels were collected from juice vendors in Varanasi, India, in the months of January 2012, 2013 and 2014, and were used in the experiments.

\subsection{Naringin extraction from peel-boiled water}

The procedure for extraction of naringin from kinnow peels is a slight variation of the method described in the literature [13]. Distilled water was added to kinnow peels in the ratio of $4: 1$. The contents were boiled for $60 \mathrm{~min}$ and filtered with a muslin cloth. Due to a high melting point $\left(166^{\circ} \mathrm{C}\right)$ and low vapour pressure $\left(0 \mathrm{mmHg}\right.$ at $\left.25^{\circ} \mathrm{C}\right)$ it is thought that there will be no loss during boiling or evaporation of solvent at the later stage. The procedure was repeated two times with the residue obtained in each step. The extracts obtained in each step were cooled down and were mixed. Potassium metabisulphite (KMS) was added (2 g/l) to prevent microorganism growth in the peel-boiled water. The preserved KPBW was used for both adsorption experiments and for recovery of naringin. The naringin extraction process is shown in figure 2 .

\subsection{Analytical procedures}

The Davis test [25] was used to analyse naringin content in the solution. In this method, a yellow coloured solution was developed using $0.1 \mathrm{ml}$ of the sample, $10 \mathrm{ml}$ of $90 \%$ diethylene glycol and $0.1 \mathrm{ml}$ of $4 \mathrm{~N} \mathrm{NaOH}$ solution. The absorbance of the coloured solution was measured using a spectrophotometer at $420 \mathrm{~nm}$. The standard calibrated graph (absorbance vs. naringin) was used to measure the naringin content in the sample.

In desorption studies, $1.0 \mathrm{ml}$ of the sample (ethanolnaringin solution) was taken, and ethanol was evaporated to get the dried sample. This dried sample was dissolved in $5.0 \mathrm{ml}$ of distilled water, and naringin concentration was measured by the Davis test as discussed above. The naringin concentration in the desorbed sample was obtained from the amount of naringin and volume of alcohol solution.

\subsection{Experimental procedure}

2.3a Adsorption-desorption experimental procedures: Small quantities of organic and inorganic impurities present in the resin were removed by the usual conditioning procedure [26], and stored in distilled water. A sample of the resin was taken, and the adhering surface moisture was removed by pressing it gently between the folds of a filter paper. This has been termed as filter-paper- 
Table 1. The characteristics of resin INDION PA-500.

\begin{tabular}{lc}
\hline Appearance & $\begin{array}{c}\text { Translucent beads } \\
\text { Matrix }\end{array}$ \\
Moisture holding capacity & Styrene divinylbenzene copolymer \\
Shipping weight & $62-69 \%$ \\
Particle size range & $\mathrm{kg} / \mathrm{m}^{3}$ approximately \\
Uniformity coefficient & $0.3-0.85 \mathrm{~mm}$ \\
Effective size & 1.8. maximum \\
Surface area & $0.40-0.50 \mathrm{~mm}$ \\
Porosity & $\geq 500 \mathrm{~m}^{2} / \mathrm{g}$ \\
Maximum operating & 0.45 \\
$\quad$ temperature & $250^{\circ} \mathrm{C}$ \\
Operating pH range & $0-14$ \\
Resistance to reducing & Good \\
agents & Gesistance to oxidizing \\
agents & Generally good, chlorine should be \\
\hline
\end{tabular}

Product data sheet of Indion resin (PA-500), issued by ION EXCHANGE India Limited. dried resin (FPD). A part of it (1-2 g) was transferred to the oven and dried at $105^{\circ} \mathrm{C}$ for $48 \mathrm{~h}$, followed by cooling in a desiccator. The dried resin was called as oven-dried resin (ODR). The solid content is defined as the ratio of the weight of ODR resin to FPD resin. During every adsorption equilibrium and kinetics experiment, the solid content was determined for a specific specimen of the FPD resin. The number of adsorption sites depends on the area per unit dry mass. The mass of dry resin will give the actual representation of mass of adsorbent. Therefore, solid content will be helpful in determining the true weight of the resin used in adsorption experiments from FPD resin mass used. For the same specimen of FPD sample, the solid content was determined in duplicate, and it was reproducible within experimental limits. Though the experiments were carried out with FPD resin, the calculations were done on the basis of ODR as per the standard practice. To prevent the column from the protein deposition, the conditioned resin was treated with citric acid of concentration $4 \mathrm{~g} / \mathrm{l}$.

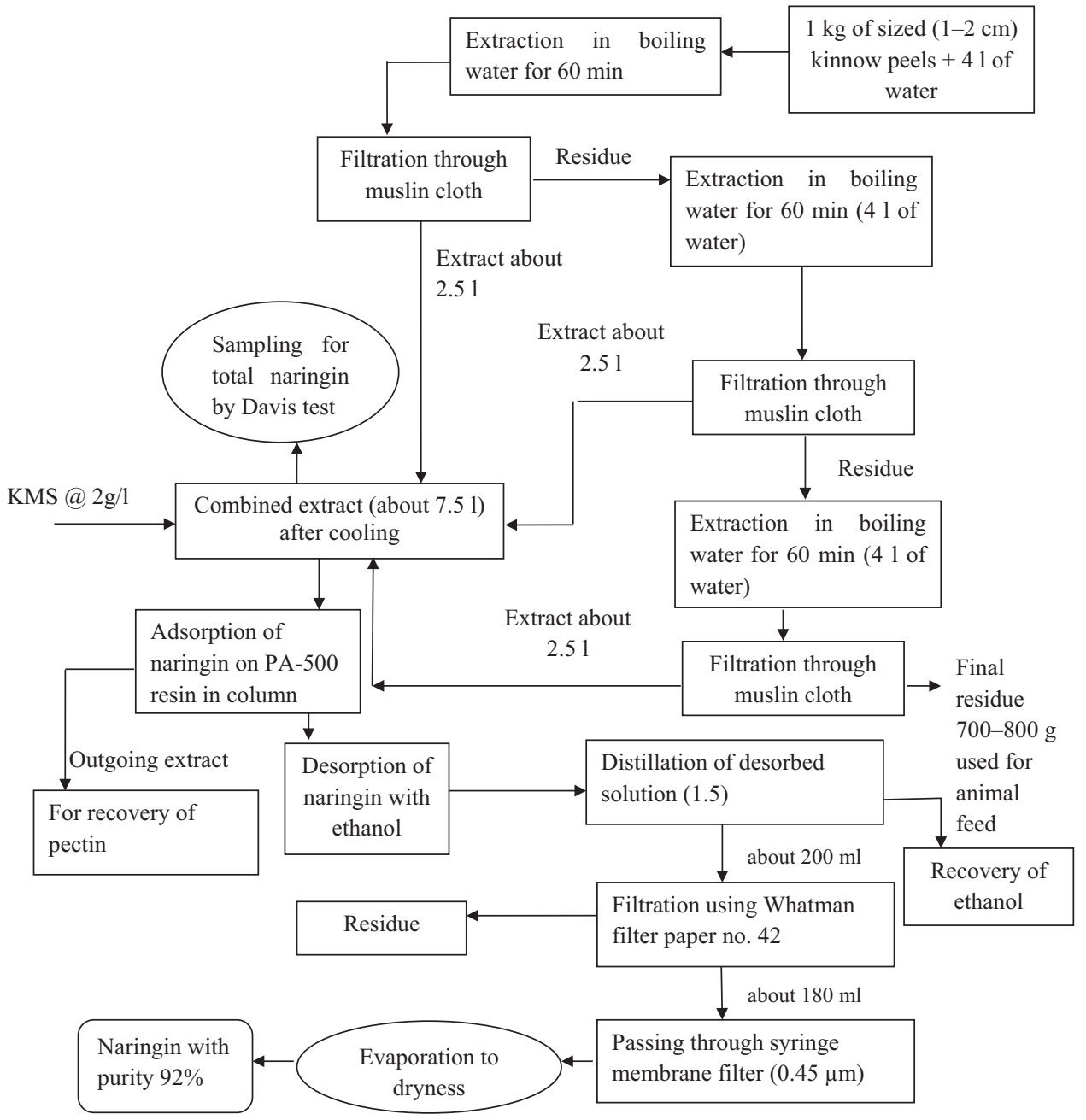

Figure 2. Process flow sheet for naringin extraction from kinnow peels. 


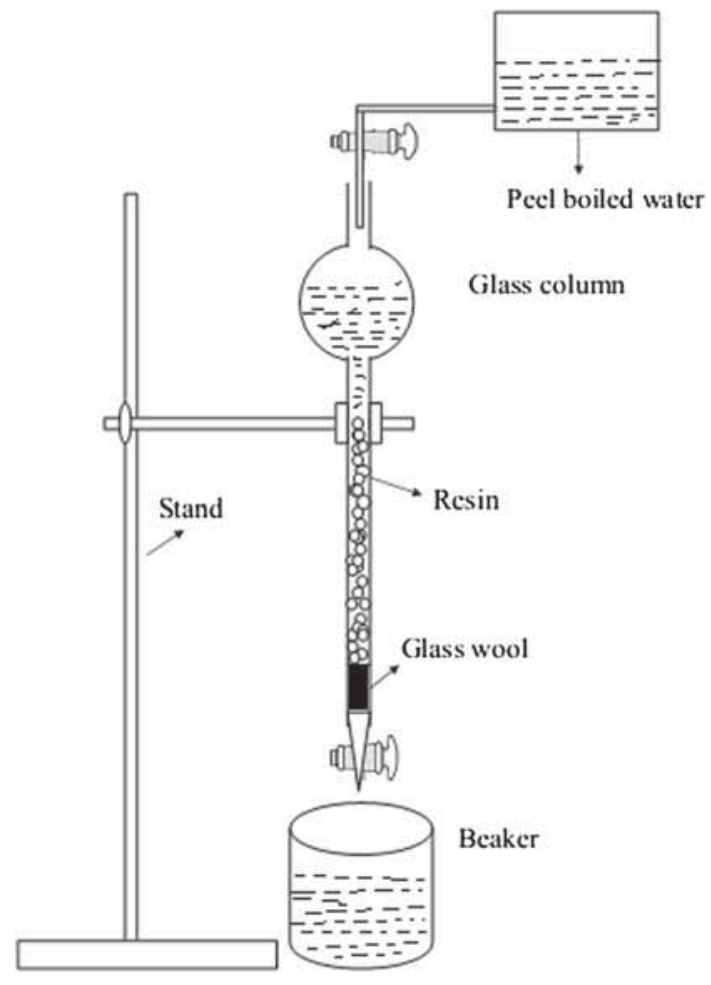

Figure 3. Set-up for column studies.

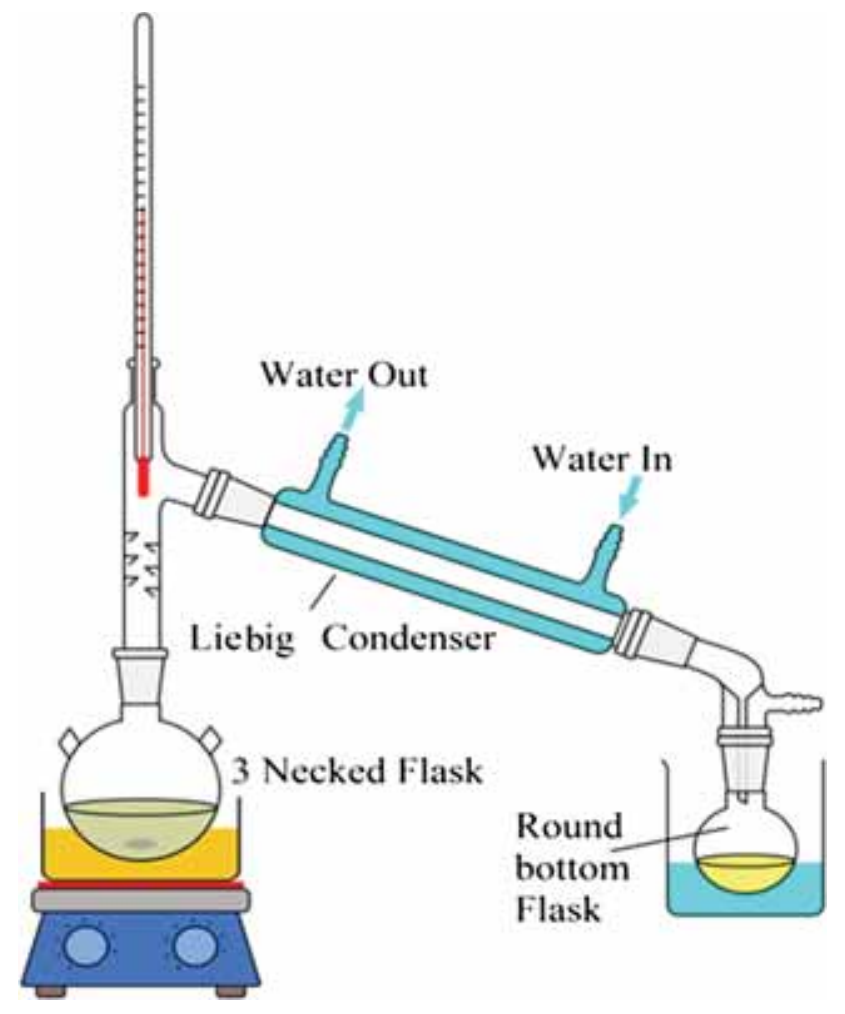

Figure 4. Set-up for simple distillation. 2.3b Equilibrium studies: Known amounts of resin and KPBW containing adsorbate (naringin) were added to a conical flask with stoppers, and allowed to achieve equilibrium. After a few initial runs, it was observed that it took less than $24 \mathrm{~h}$ to reach equilibrium. As there was no loss of naringin, mass balance is used to determine the amount of naringin adsorbed on the resin given below. The studies were carried out at temperature $30 \pm 1^{\circ} \mathrm{C}$ :

$$
q_{\mathrm{e}}=\frac{V\left(C_{\mathrm{o}}-C_{\mathrm{e}}\right)}{w}
$$

where $q_{\mathrm{e}}$ is the amount of naringin adsorbed, $V$ the volume of solution $(\mathrm{KPBW}), C_{\mathrm{o}}$ the initial concentration of naringin in solution, $C_{\mathrm{e}}$ the final concentration of naringin in solution and $w$ the weight of resin.

2.3c Batch kinetic studies: Batch kinetic studies were carried out in a three-necked round-bottomed $500 \mathrm{ml}$ glass flask fitted with a Teflon stirrer. Preliminary investigations showed that there was no effect of stirrer speed on naringin pickup on the resin at $250 \pm 10 \mathrm{rpm}$. KPBW (450 ml) was transferred to the flask, and the known amount of resin was added to it. The stirrer speed was kept at $250 \pm 10 \mathrm{rpm}$ to eliminate mass transfer as the limiting step. Samples of KPBW were drawn at different time intervals to know the variation of naringin concentration in the flask with time.

2.3d Desorption equilibrium studies: A known amount of the resin saturated with naringin, obtained from column adsorption with KPBW and pure ethanol, was transferred to a flask and placed on a shaker for at least $24 \mathrm{~h}$, after which equilibrium was achieved. The concentration of the naringin desorbed was estimated using the following mass balance equation:

$$
W^{\mathrm{I}}\left(q_{\mathrm{od}}-q_{\mathrm{ed}}\right)=V_{\mathrm{e}} C_{\mathrm{ed}}
$$

where $W^{\mathrm{I}}=\left(w_{\mathrm{n}}+w_{\mathrm{r}}\right)$ is the weight of resin saturated with naringin, $w_{\mathrm{n}}$ the weight of naringin adsorbed on resin, $w_{\mathrm{r}}$ the weight of resin without naringin, $q_{\text {od }}$ the initial naringin content in resin, $q_{\text {ed }}$ the amount of species desorbed from the resin in ethanol at equilibrium, $V_{\mathrm{e}}$ the volume of ethanol and $C_{\text {ed }}$ the final concentration of naringin at equilibrium in alcohol solution.

$W^{\mathrm{I}}$ is obtained from peel-boiled water column studies and obtained from the equilibrium data, corresponding to the concentration of KPBW used in adsorption column study.

2.3e Desorption kinetic studies: Desorption batch kinetic studies were carried out using the procedure followed for batch kinetic studies. However, naringin-saturated resin was used in place of resin. Ethanol was used as a desorbing solvent.

2.3f Adsorption desorption column procedures: The experimental set-up is shown in figure 3. It consists of a glass column with ID of $20 \mathrm{~mm}$. Swollen resin (about 


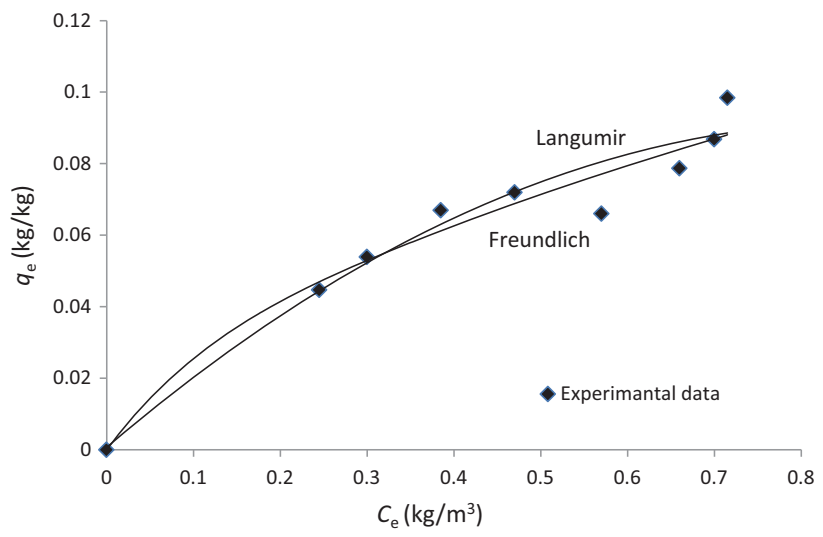

Figure 5. Comparison of various adsorption isotherms with experimental data.

Table 2. Isotherm parameters for adsorption of naringin on resins PA-500.

\begin{tabular}{cccc}
\hline Langmuir & $a$ & $b$ & $R^{2}$ \\
\hline Freundlich & 0.252 & 1.432 & 0.91 \\
\hline & $K_{\mathrm{f}}$ & $n$ & $R^{2}$ \\
\hline
\end{tabular}

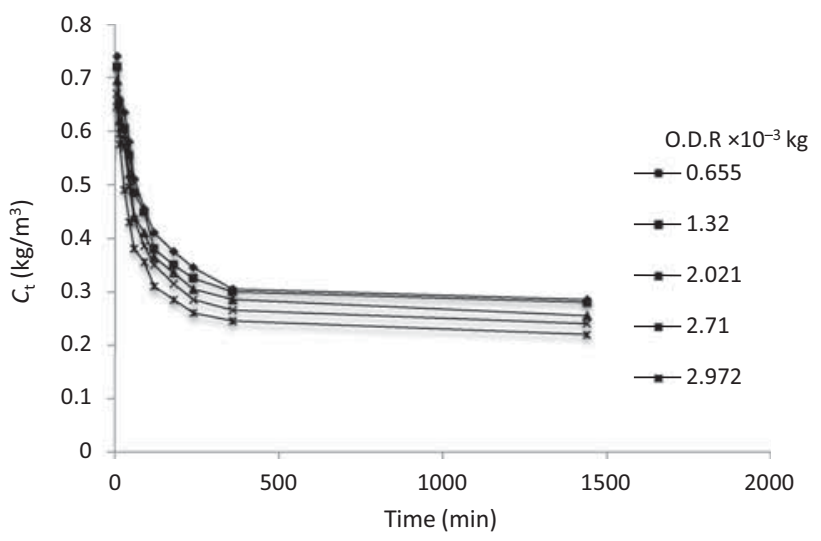

Figure 6. Kinetic studies for adsorption of naringin from kinnow-peel-boiled water on resin, $C_{t}$ vs. $t$.

$150 \mathrm{~g}$ ) was filled in it. Two liters of citric acid of concentration $4 \mathrm{~g} / \mathrm{l}$ were passed through the above resin at a flow rate of $2.0 \mathrm{ml} / \mathrm{min}$ to treat the resin. The citric acid solution was drained. The peel-boiled water was passed through the column containing the resin at a flow rate of $2 \mathrm{ml} / \mathrm{min}$ till the resin saturated with naringin, i.e., the concentration of naringin in KPBW at the inlet of the column is equal to that at the outlet. Maintaining a constant flow at the outlet is of importance. The constant flow rates at the inlet and outlet were maintained manually so that level of KPBW in the bulb of the set-up remains almost constant.
In naringin desorption, ethanol was passed through the column containing naringin-saturated resin, until no change in the concentration of naringin was observed in the outgoing solution. The ethanol-naringin solution was collected from the bottom of the column and was used for naringin recovery. During a run about 1.51 of ethanol was passed through the column.

\subsection{Distillation of desorbed ethanol-naringin solution}

A simple distillation (figure 4) was carried out to concentrate 1.51 of the desorbed ethanol-naringin solution to about $200 \mathrm{ml}$. A Whatman filter paper no. 42 was used to filter the concentrated ethanol-naringin solution. Then the filtrate was passed through a polyester-membrane syringe filter (size $0.45 \mu \mathrm{m}$ ) followed by evaporation to recover naringin as a solid.

\section{Results and discussion}

The naringin content in extracts of kinnow peels for 3 years (2012, 2013 and 2014) was determined and found to be $0.810,0.780$ and $0.750 \mathrm{~kg} / \mathrm{m}^{3}$, respectively. In all equilibrium, kinetics studies during adsorption and desorption, data for the year 2013 were used unless specified.

\subsection{Adsorption studies}

3.1a Equilibrium studies: Adsorption equilibrium data for the year $2013\left(q_{\mathrm{e}}\right.$ vs. $C_{\mathrm{e}}$ ) are shown in figure 5. The data correlated well with Freundlich and Langmuir adsorption isotherms:

Freundlich isotherm [27] is given by

$$
q_{\mathrm{e}}=K_{\mathrm{f}} C_{\mathrm{e}}^{1 / n}
$$

where $K_{\mathrm{f}}$ and $n$ are Freundlich isotherm constants (dimensionless). The values of $C_{\mathrm{e}}$ and $q_{\mathrm{e}}$ are in $\mathrm{kg} / \mathrm{m}^{3}$ and $\mathrm{kg} / \mathrm{kg}$.

Langmuir adsorption isotherm [28] is given by

$$
q_{\mathrm{e}}=\frac{a C_{\mathrm{e}}}{1+b C_{\mathrm{e}}}
$$

where $q_{\mathrm{e}}$ is the amount of naringin adsorbed at equilibrium $\left(\mathrm{kg} / \mathrm{m}^{3}\right), C_{\mathrm{e}}$ the final concentration of naringin in solution $\left(\mathrm{kg} / \mathrm{m}^{3}\right)$ and $a, b$ are Langmuir isotherm constants. The units of $a$ and $b$ are $\mathrm{m}^{3} / \mathrm{kg}$ and $\mathrm{m}^{3} / \mathrm{kg}$, respectively.

The estimated values of both isotherm parameters are presented in table 2. From the $R^{2}$ values, the Langmuir adsorption isotherm represented data better than Freundlich isotherm. Similar findings were reported by other studies (flavonoid adsorption on macroporous resins) [22, 24]. The amount of naringin adsorbed by $1 \mathrm{~kg}$ of dry resin $q_{\mathrm{emax}}$ is 

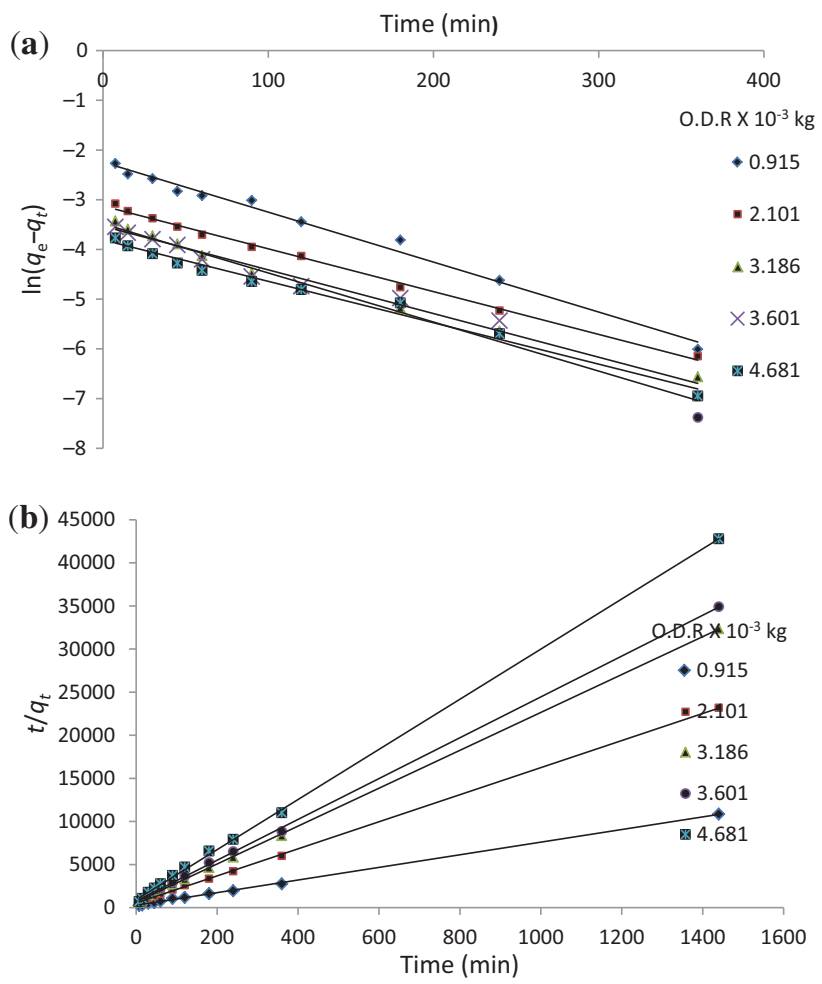

Figure 7. Pseudo-first- and second-order plots for naringin adsorption onto the resin PA-500. (a) Lagergren plot $\ln \left(q_{\mathrm{e}}-q_{t}\right)$ vs time $(t)$. (b) Pseudo-second-order plot $t / q_{t}$ vs. time $(t)$.

$0.1765 \mathrm{~kg}$, i.e., adsorption capacity is $0.1765 \mathrm{~kg}$ of naringin $/ \mathrm{kg}$ of dry resin as calculated from Langmuir constants. Kinnow peel extract contains several compounds. During adsorption, all compounds reach the surface, where they are attached to the active site. Reduction of mass-transfer resistance was an obvious choice as naringin molecules are much larger than other molecules; otherwise, the active sites would have occupied more fraction of active sites on the adsorbents. 3.1b Batch kinetic studies: The concentration of naringin in the solution as a function of time during adsorption for various amounts of oven-dried resin is presented in figure 6. It may be observed that the rate of change in concentration of a solution is more when the weight of the resin used is high. Almost more than $80 \%$ adsorption takes place in first $6 \mathrm{~h}$ in all runs. Adsorption of naringin increased with contact time.

The adsorption kinetic data were analysed using two kinetic models: (i) pseudo-first order and (ii) pseudo-second order.

The pseudo-first-order rate equation [29] is

$$
\frac{d q_{t}}{d t}=k_{\mathrm{f}}\left(q_{\mathrm{e}}-q_{t}\right)
$$

Equation (5) can be expressed as

$$
\ln \left(q_{\mathrm{e}}-q_{t}\right)=\ln q_{\mathrm{e}}-k_{\mathrm{f}} t
$$

The pseudo-second-order rate equation [30] is

$$
\left(\frac{d q}{d t}\right)=k_{\mathrm{s}}\left(q_{\mathrm{e}}-q_{t}\right)^{2}
$$

The above expression can be expressed as

$$
\frac{t}{q_{t}}=\frac{1}{k_{\mathrm{s}} q_{\mathrm{e}}^{2}}+\frac{t}{q_{\mathrm{e}}}
$$

where $q_{t}$ is the amount of naringin adsorbed at time $t(\mathrm{~kg}$ naringin $/ \mathrm{kg}$-resin), $q_{\mathrm{e}}$ the amount of naringin adsorbed at equilibrium (kg-naringin/kg-resin), $k_{\mathrm{f}}$ the rate constant of the pseudo-first-order adsorption reaction $\left(\mathrm{min}^{-1}\right)$ and $k_{\mathrm{s}}$ the rate constant for the pseudo-second-order adsorption reaction $\left(\mathrm{kg} \mathrm{kg}^{-1} \mathrm{~min}^{-1}\right)$.

A Lagergren plot is drawn between $\ln \left(q_{\mathrm{e}}-q_{t}\right)$ and time $(t)$ and shown in figure 7(a). The values of the first-order

\begin{tabular}{|c|c|c|c|c|c|}
\hline Run & Wt. of resin O.D. $\mathrm{R} \times 10^{-3} \mathrm{~kg}$ & $k_{\mathrm{f}}\left(\min ^{-1}\right)$ & $q_{\mathrm{e}}, \mathrm{kg} / \mathrm{kg}$ (calculated) & $q_{\mathrm{e}}, \mathrm{kg} / \mathrm{kg}$ (experimental) & $R^{2}$ \\
\hline \multicolumn{6}{|c|}{ Pseudo-first order } \\
\hline 1 & 0.915 & 0.0101 & 0.1060 & 0.1326 & 0.987 \\
\hline 2 & 2.101 & 0.0086 & 0.0438 & 0.0621 & 0.995 \\
\hline 3 & 3.186 & 0.0087 & 0.0292 & 0.0444 & 0.984 \\
\hline 4 & 3.601 & 0.0098 & 0.0305 & 0.0412 & 0.959 \\
\hline \multirow[t]{2}{*}{5} & 4.681 & 0.0083 & 0.0221 & 0.0336 & 0.982 \\
\hline & & $\begin{array}{c}k_{\mathrm{s}} \\
\left(\min ^{-1}\right)\end{array}$ & & & \\
\hline \multicolumn{6}{|c|}{ Pseudo-second order } \\
\hline 1 & 0.915 & 0.199 & 0.1364 & 0.1326 & 0.999 \\
\hline 2 & 2.101 & 0.448 & 0.0637 & 0.0621 & 0.999 \\
\hline 3 & 3.186 & 0.720 & 0.0455 & 0.0444 & 0.999 \\
\hline 4 & 3.601 & 0.729 & 0.0422 & 0.0412 & 0.999 \\
\hline 5 & 4.681 & 0.917 & 0.0343 & 0.0336 & 0.999 \\
\hline
\end{tabular}
rate constant $k_{\mathrm{f}}$ (adsorption at equilibrium) are calculated and tabulated in table 3 . From the plot of figure $7 \mathrm{a}$ and

Table 3. Adsorption kinetic parameters for adsorption of naringin on resins PA-500. 


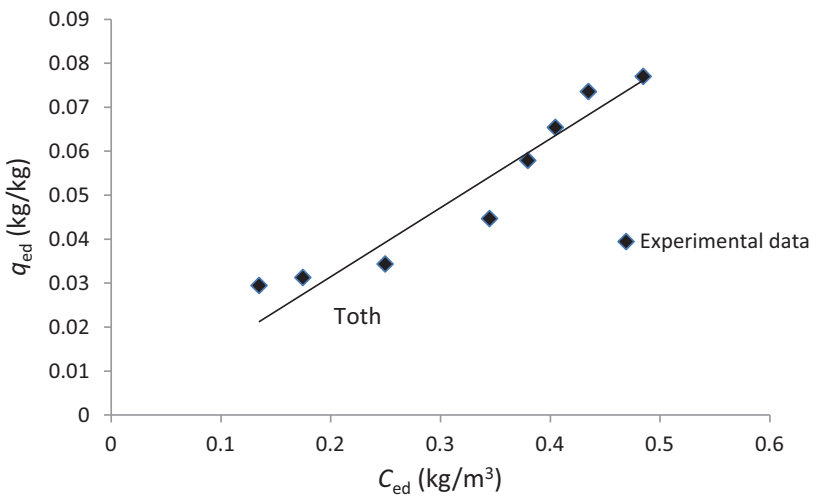

Figure 8. Desoption equilibrium studies from adsorbed resin PA500 to ethanol solution.

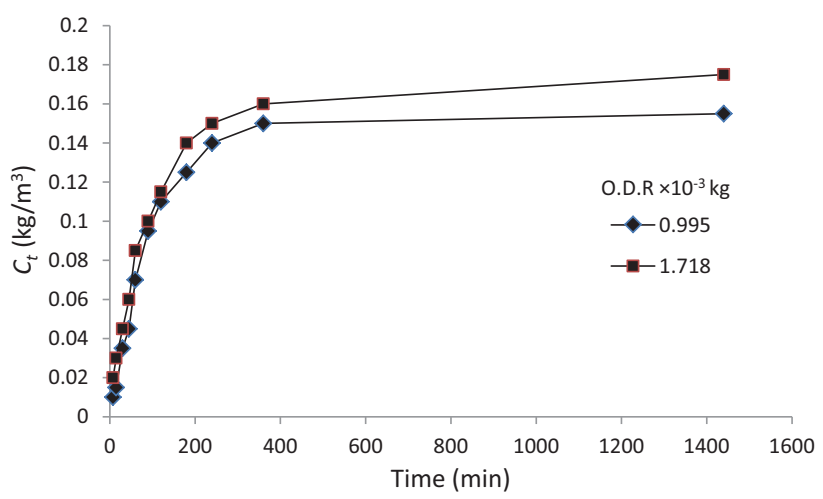

Figure 9. Kinetic studies for desorption studies with alcohol to recover naringin, $C_{t}$ vs. $t$.

table 3, the correlation coefficients $\left(R^{2}\right)$ for the first-order kinetic model are quite high, but the calculated $q_{\mathrm{e}}$ values do not give reasonable values; hence the adsorption of naringin on PA-500 resin does not fit this equation.

The values of the second-order rate constant $k_{\mathrm{s}}$ and adsorption at equilibrium estimated using linear plots of $t / q_{t}$ against time $(t)$ as shown in figure $7 \mathrm{~b}$ are presented in table 3 . The correlation coefficients of all the data are found to be in the range of $R^{2}=0.99$. The calculated and experimental values of the amount of naringin adsorbed by the resin are very close to each other for the pseudo-second-order kinetic model. Therefore, naringin adsorption on resin follows the pseudo-second-order kinetic model. The pseudo-secondorder kinetic has been successfully applied to the adsorption of flavonoids from aqueous solutions. Some studies of the kinetics of flavonoids adsorption onto various adsorbents also follow pseudo-second-order model [17, 20, 22, 23].

\subsection{Desorption studies}

3.2a Equilibrium studies: The desorption equilibrium curve as shown in figure 8 shows a trend as expected and desorption is favourable with alcohol but does not approach completion. When the concentration of naringin in alcohol is about $0.26 \mathrm{~kg} / \mathrm{m}^{3}$ the naringin in adsorbent is $0.034 \mathrm{~kg} /$ $\mathrm{kg}$ of resin; it reaches $0.028 \mathrm{~kg} / \mathrm{kg}$ of resin at concentration $0.18 \mathrm{~kg} / \mathrm{m}^{3}$ and the curve flattens to a lower value $0.14 \mathrm{~kg} /$ $\mathrm{m}^{3}$ of alcohol concentration. This means that naringin cannot be desorbed beyond this $(0.028 \mathrm{~kg} / \mathrm{kg}$ of resin) concentration, or it is permanently adsorbed for eluent ethanol. The desorption equilibrium experimental data could be correlated with the modified Toth isotherm [31]

$$
q_{\text {ed }}=\frac{A C_{\text {ed }}}{\left(B+C_{\text {ed }}^{D}\right)^{1 / D}}
$$

where $q_{\text {ed }}$ is the amount of naringin desorbed at equilibrium ( $\mathrm{kg} / \mathrm{kg}$ of resin) and $C_{\mathrm{ed}}$ the final concentration of naringin in ethanol $\left(\mathrm{kg} / \mathrm{m}^{3}\right) . A, B$ and $D$ are Toth isotherm constants.

Plotting Eq. (9) is not possible because of the three unknown parameters contained within the equation. Therefore, a minimization procedure is adopted to maximize the correlation coefficient $R^{2}$ between the theoretical data for $q_{\text {ed }}$ predicted from Eq. (9) Using "SOLVER" add-in for "EXCEL" and the experimental data. The value of the correlation coefficient $R^{2}$ is found to be 0.916 . The values of Toth isotherm constants $A, B$ and $D$ are found to be $0.245,7.639$ and 4.5541 , respectively.

3.2b Batch kinetic studies: From figure 9, it can be observed that most of the desorption of naringin from the resin (saturated with naringin after passing through peelboiled water) to alcohol solution takes place in the first $200 \mathrm{~min}$; it reaches almost $90 \%$ of the final value. The initial value of naringin in ethanol rises sharply and then slowly the rate of concentration change declines, which is as per expectation because the driving force reduces with time.

To find out the mechanism of naringin desorption from the surface of the polymeric resin PA-500, the following kinetic model equations are used to correlate experimental desorption data. The kinetic models considered are firstorder rate equation and second-order rate equation. Although these have been derived and used to relate kinetics of chemical equation, the same are being tried to correlate the kinetic desorption data.

First-order rate equation [32]:

$$
\frac{d q_{t \mathrm{~d}}}{d t}=-k_{\mathrm{fd}} q_{t \mathrm{~d}}
$$

The above equation can be expressed as

$$
\ln \left(q_{t \mathrm{~d}}\right)=\ln \left(q_{\mathrm{od}}\right)-k_{\mathrm{fd}} t
$$

where $k_{\mathrm{fd}}$ is the rate constant of the first-order desorption reaction $\left(\mathrm{min}^{-1}\right)$.

Second-order rate equation [32]: 

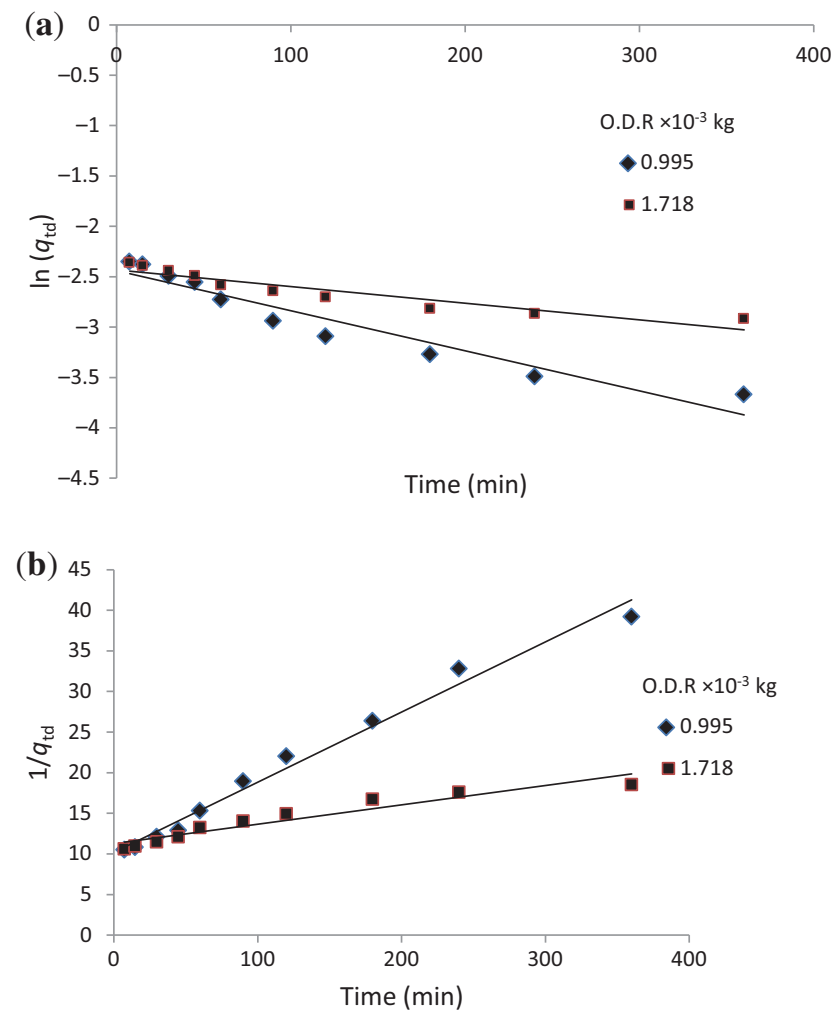

Figure 10. First- and second-order plots for naringin desorption onto the ethanol from resin PA-500. (a) First-order rate equation plot $\ln \left(q_{t \mathrm{~d}}\right)$ vs time $(t)$ for desorption. (b) First-order rate equation plot $t / q_{t \mathrm{~d}}$ vs time $(t)$ for desorption.

$$
\frac{d q_{t \mathrm{~d}}}{d t}=-k_{\mathrm{sd}} q_{t \mathrm{~d}}^{2} .
$$

This equation can be rewritten as

$$
\frac{1}{q_{t \mathrm{~d}}}=k_{\mathrm{sd}} t+\frac{1}{q_{\mathrm{od}}}
$$

where $k_{\mathrm{sd}}$ is the rate constant of the second-order desorption reaction $\left(\mathrm{kg} \mathrm{kg}^{-1} \mathrm{~min}^{-1}\right), q_{t \mathrm{~d}}$ the amount of naringin desorbed at time $t$ and $q_{\text {od }}$ the amount of naringin present in the resin before desorption.
The values of the first-order rate constant $k_{\mathrm{fd}}$ for desorption of naringin from the resin PA-500 onto ethanol were calculated from the linear plots of $\ln \left(q_{t \mathrm{~d}}\right)$ vs time (figure 10a) and are tabulated in table 4. The value of $R^{2}$ indicates that the rate of desorption of naringin from the resin to ethanol does not follow the first-order equation.

The values of the second-order rate constant $k_{\mathrm{sd}}$ and $q_{\text {od }}$ (presented in table 4) are estimated using linear plots of $1 /$ $q_{t \mathrm{~d}}$ against time $(t)$ as shown in figure $10 \mathrm{~b}$. Based on the goodness of fit $\left(R^{2}>0.95\right)$, desorption kinetics follows the second-order rate equation better.

The equilibrium data give the minimum amount of adsorbent required for a particular adsorbate load. The kinetic data tell the contact time between adsorbent and adsorbate solution for feasible operation. These data can be used in scale-up and design of a column (height of adsorbent and the diameter of the column, at a given capacity (flow rate of KPBW) in the column). The desorption equilibrium data can be used to know the minimum amount of eluent (ethanol) required. The desorption kinetic data can be used to know the contact time between the used resin (containing naringin) and ethanol and hence the flow rate of ethanol required during desorption.

\subsection{Recovery of naringin}

Recovery of naringin was calculated by using the formula given below:

$$
\begin{aligned}
& \text { recovery of crude naringin } \\
& =\frac{\text { wt. of crude naringin } \times \text { purity }}{\text { liters of } K P B W \text { passed } \times \text { conc. of naringin in } K P B W} .
\end{aligned}
$$

Recovery and purity of naringin in the years 2012, 2013 and 2014 are tabulated along with the values reported in the literature for recovery and purity of naringin from different citrus fruit peels and different methods in table 5. Though the recovery is lesser than that obtained by using more sophisticated processes such as ultrasonic or $\mathrm{SC}-\mathrm{CO}_{2}$

\begin{tabular}{|c|c|c|c|c|c|}
\hline Run & Wt. of resin O.D. $\mathrm{R} \times 10^{-3} \mathrm{~kg}$ & $k_{\mathrm{fd}}\left(\min ^{-1}\right)$ & $q_{\text {od }}, \mathrm{kg} / \mathrm{kg}$ (calculated) & $q_{\text {od }}, \mathrm{kg} / \mathrm{kg}$ (experimental) & $R^{2}$ \\
\hline \multicolumn{6}{|c|}{ First-order rate equation } \\
\hline 1 & 0.995 & 0.003 & 0.087 & 0.095 & 0.913 \\
\hline \multirow[t]{2}{*}{$\underline{2}$} & 1.718 & 0.001 & 0.087 & 0.094 & 0.859 \\
\hline & & $\begin{array}{c}k_{\mathrm{sd}} \\
\left(\min ^{-1}\right)\end{array}$ & & & \\
\hline \multicolumn{6}{|c|}{ Second-order rate equation } \\
\hline 1 & 0.995 & 0.086 & 0.098 & 0.095 & 0.982 \\
\hline 2 & 1.718 & 0.023 & 0.090 & 0.094 & 0.952 \\
\hline
\end{tabular}
extraction, due to high purity of the product obtained, the simple adsorption method studied in the present work may

Table 4. Desorption kinetic parameters for desorption of naringin from resin PA-500. 
Table 5. Recovery and purity of Naringin in different methods with different fruits reported in literature.

\begin{tabular}{|c|c|c|c|c|c|c|}
\hline S. no & Name of the peel & Year & Method of extraction & Recovery & Purity & Reference \\
\hline \multirow[t]{3}{*}{1} & $\begin{array}{c}\text { Kinnow (Citrus reticulata Blanco) } \\
\text { peels }\end{array}$ & 2012 & Adsorption followed by desorption & $49.4 \%$ & $91 \%$ & $\begin{array}{r}\text { Present } \\
\text { study }\end{array}$ \\
\hline & & 2013 & & $48.2 \%$ & $94 \%$ & \\
\hline & & 2014 & & $48.1 \%$ & $93 \%$ & \\
\hline 2 & $\begin{array}{c}\text { Grapefruit (Citrus paradisi Macf.) } \\
\text { seeds }\end{array}$ & & $\mathrm{SC}-\mathrm{CO}_{2}$ extraction & $0.2 \mathrm{mg} / \mathrm{g}$ & - & [6] \\
\hline 3 & Citrus junos peels & & $\mathrm{SC}-\mathrm{CO}_{2}$ extraction & $50-60 \%$ & - & [7] \\
\hline 4 & Citrus paradise peel & & $\mathrm{SC}-\mathrm{CO}_{2}$ extraction & $14.2 \%$ & - & [8] \\
\hline 5 & Bergamot peel & & $\begin{array}{c}\text { Water extraction followed by } \\
\text { crystallization }\end{array}$ & $1.66-3.80 \%$ & $95 \%$ & [9] \\
\hline 6 & Pomelo (Citrus grandis) peel & & $\begin{array}{c}\text { Water extraction followed by } \\
\text { crystallization }\end{array}$ & $2-3 \%$ & $98 \%$ & {$[10]$} \\
\hline 7 & Citrus grandis Tomentosa peels & & Ultrasonic extraction & $82 \%$ & - & [11] \\
\hline 8 & Pomelo peel & & Ultrasonic extraction & - & $78 \%$ & [12] \\
\hline 9 & Bergamot peels & & Adsorption followed by desorption & $93 \%$ & & [13] \\
\hline 10 & Shaddock peels & & Adsorption followed by desorption & - & - & [5] \\
\hline
\end{tabular}

be preferred due to lesser initial cost involved than that in these processes. High-quality naringin was achieved in this process, which can be used as a raw material for preparation of the sweetener (when naringin was treated with potassium hydroxide, it became a dihydrochalcone which was roughly 300-1800 times sweeter than sugar at threshold concentrations). Present adsorption on the indigenous resin is inexpensive relative to XAD-16, and it may be feasible to use the process even at small scale.

\section{Conclusion}

A new process technology for recovery of naringin from kinnow peels was developed. The naringin obtained was of high purity and yield. The method used a low-cost solvent (ethanol) and involved simple operations. Adsorption isotherms for naringin on resin Indion PA-500 have best described by the Langmuir isotherm. The adsorption kinetics followed a pseudo-second-order rate kinetic model. Desorption of naringin by using ethanol from resin followed the Toth isotherm. The desorption kinetics observed a second-order rate equation. The naringin obtained was 91-94\% w/w pure.

\section{References}

[1] Puri M, Kaur A, Schwarz W H, Singh S and Kennedy J F 2011 Molecular characterization and enzymatic hydrolysis of naringin extracted from kinnow peel waste. Int. J. Biol. Macromol. 48: 58-62

[2] Aggarwal P and Sandhu K S 2003 Effect of harvesting time on physico-chemical properties of juice components of Kinnow. J. Food Sci. Technol. 40: 666-668
[3] http://www.lookchem.com/Naringin/

[4] Gorinstein S, Huang D, Leontowicz H, Leontowicz M, Yamamoto K, Soliva-Fortuny R, Belloso O M, Martinez Ayala A L and Trakhtenberg S 2006 Determination of naringin and hesperidin in citrus fruit by high-performance liquid chromatography: the antioxidant potential of citrus fruit. Acta Chromatogr. 17: 108-224

[5] Jiang X, Zhou J and Zhou C 2006 Study on adsorption and separation of naringin with macroporous resin. Front. Chem. China 1(1): 77-81

[6] Yu J, Dandekar D V, Toledo R T, Singh R K and Patil B S 2007 Supercritical fluid extraction of limonoids and naringin from grapefruit (Citrus paradisi Macf.) seeds. Food Chem. 105(3): 1026-1031

[7] Suetsugu T, Iwai H, Tanaka M, Hoshino M, Quitain A, Sasaki M and Goto M 2013 Extraction of citrus flavonoids from peel of citrus junos using supercritical carbon dioxide with polar solvent. Chem. Eng. Sci. 1(4): 87-90

[8] Giannuzzo A N, Boggetti H J, Nazareno M A and Mishima H T 2003 Supercritical fluid extraction of naringin from the peel of Citrus paradisi. Phytochem. Anal. 14(4): 221-223

[9] Tripodo M M, Lanuzza F and Mondello F 2007 Utilization of a citrus industry waste: bergamot peels. Forum Ware Int. 2: 20-26

[10] Sudto K, Pornpakakul S and Wanichwecharungruang S 2009 An efficient method for the large scale isolation of naringin from pomelo (Citrus grandis) peel. Int. J. Food Sci. Technol. 44(9): 1737-1742

[11] Kong F, Bi Y, Yan C and Zeng Z 2013 Orthogonal test design for optimization of the ultrasonic extraction of naringin from Citrus grandis Tomentosa. J. Med. Plants 7(12): $720-726$

[12] Tang D M, Zhu C F, Zhong S A and Zhou M D 2011 Extraction of naringin from pomelo peels as dihydrochalcone's precursor. J. Sep. Sci. 34(1): 113-117

[13] Calvarano M, Postorino E, Gionfriddo F, Calvarano I, Bovalo F and Calabro G 1996 Naringin extraction from exhausted bergamot peels. Perfumer Flavorist 21(5): 1-4 
[14] Shaw P E, Baines L, Milnes B A and Agmon G 2000 Citrus limonoids. In: Commercial debittering processes to upgrade quality of citrus juice products. ACS Symposium Series. vol. 758, pp. 120-131

[15] Geng X, Ren P, Pi G, Shi R, Yuan Z and Wang C 2009 High selective purification of flavonoids from natural plants based on polymeric adsorbent with hydrogen-bonding interaction. J. Chromatogr. A 1216(47): 8331-8338

[16] Dong Y, Zhao M, Sun-Waterhouse D, Zhuang M, Chen H, Feng $\mathrm{M}$ and Lin L 2015 Absorption and desorption behaviour of the flavonoids from Glycyrrhiza glabra $L$. leaf on macroporous adsorption resins. Food Chem. 168: 538-545

[17] Deka H and Saikia M D 2015 Structural and thermodynamic factors on adsorptive interaction of certain flavonoids onto polymeric resins and activated carbon. Colloids Surf. A Physicochem. Eng. Asp. 469: 51-59

[18] Silva E M, Rogez H, Da Silva I Q and Larondelle Y 2013 Improving the desorption of Inga edulis flavonoids from macroporous resin: towards a new model to concentrate bioactive compounds. Food Bioprod. Process. 91(4): 558-564.

[19] Ye H, Chen Z, Liu Y, Lou S and Di D 2014 Comparison of the adsorption behavior of flavonoids on three macroporous adsorption resins modified with hydrogen-bond groups. $J$. Appl. Polym. Sci. 131(10): 1-13

[20] Geerkens C H, Matejka A E, Schweiggert R M, Kammerer D $\mathrm{R}$ and Carle R 2015 Optimization of polyphenol recovery from mango peel extracts by assessing food-grade adsorbent and ion exchange resins and adsorption parameters using a D-optimal design. Eur. Food Res. Technol. 241(5): 627-636

[21] Li Y, Liu J, Cao R, Deng S and Lu X 2013 Adsorption of myricetrin, puerarin, naringin, rutin, and neohesperidin dihydrochalcone flavonoids on macroporous resins. J. Chem. Eng. Data 58(9): 2527-2537

[22] Yao L, Zhang N, Wang C and Wang C 2015 Highly selective separation and purification of anthocyanins from bilberry based on a macroporous polymeric adsorbent. $J$. Agric. Food Chem. 63(13): 3543-3550

[23] Sandhu A K and Gu L 2013 Adsorption/desorption characteristics and separation of anthocyanins from Muscadine (Vitis rotundifolia) juice pomace by use of macroporous adsorbent resins. J. Agric. Food Chem. 61(7): 1441-1448

[24] Manlan M, Matthews R F, Rouseff R L, Littell R C, Marshall M R, Moye H A and Teixeira A A 1990 Evaluation of the properties of polystyrene divinylbenzene adsorbents for debittering grapefruit juice. J. Food Sci. 55(2): 440-445

[25] Davis W B 1947 Determination of flavanones in citrus fruits. Anal. Chem. 19(7): 476-478

[26] Helfferich F G 1962 Ion exchange. New York: McGraw Hill Book Company Inc

[27] Freundlich H 1907 Uber die adsorption in Losungen. J. Phys. Chem. 57: 385-470

[28] Langmuir I 1916 The constitution and fundamental properties of solids and liquids. J. Am. Chem. Soc. 38: 2221

[29] Lagergren S 1898 Zurtheorie der sogenannten adsorption gelosterstoffe. Kungliga Svenska Vetenskapsakademiens. Handlingar 24: 1-39

[30] Ho Y S and McKay G 1998 Kinetic model for lead (II) sorption onto peat. Adsorpt. Sci. Technol. 16: 243-255

[31] Toth J 1971 State equations of the solid gas interface layer. Acta Chem. Acad. Hung. 69: 311-317

[32] Qian W, Wu J, Yang L, Lin X, Chen Y, Chen X, Bai J, Xie J and Ying H 2012 Modeling the cAMP desorption process from an anion exchange chromatography column. Chem. Eng. Sci. 80: 317-325 